\title{
PROCESSO DE ETIQUETAGEM PARA IMPLANTAÇÃO DA TECNOLOGIA RFID NA BIBLIOTECA DO CENTRO UNIVERSITÁRIO UNIVATES
}

\begin{tabular}{c}
\hline LABELING PROCESS FOR RFID TECHNOLOGY IMPLEMENTATION IN LIBRARY OF \\
CENTRO UNIVERSITÁRIO UNIVATES \\
\hline PROCESO DE ETIQUETADO PARA IMPLANTACIÓN DE TECNOLOGÍA RFID EN LA \\
BIBLIOTECA DEL CENTRO UNIVERSITÁRIO UNIVATES
\end{tabular}

Nalin Ferreira da Silveira', Willian Valmorbida ${ }^{2}$

\section{RESUMO}

A tecnologia de identificação por radiofrequência (RFID) tem se destacado como uma ferramenta para automação, segurança e gestão de acervos de bibliotecas. O presente artigo descreve o processo inicial de implantação da tecnologia RFID no acervo da Biblioteca do Centro Universitário Univates (UNIVATES), evidenciando os recursos humanos e de informática envolvidos. O tempo entre planejamento e execução da gravação e etiquetagem ocorreu no período de novembro de 2013 a março de 2014. Conclui-se que processo de preparação do acervo para receber esta tecnologia é demorado e custoso, entretanto, o adequado planejamento, assim como a utilização de recursos da tecnologia da informação que possibilitem gerenciar todo o processo, permitem maior confiabilidade e agilidade.

PALAVRAS-CHAVE: Identificação por radiofrequência. Biblioteca Universitária. Segurança. Fluxo de trabalho. Tecnologia da Informação.

\section{ABSTRACT}

The Radio-Frequency Identification (RFID) Technology has emerged as a tool for automation, security and management of library collections. This article describes the initial process of RFID labels deploying in the Library of Centro Universitário Univates (UNIVATES), describing human and computer resources involved. The time between planning and execution of recording and labeling occurred from November 2013 to March 2014. We conclude that the preparation process of the collection to receive this technology is prolonged and costly, however with the appropriate planning, and using resources of information technology allow greater reliability and agility.

KEYWORDS: Radio frequency identification. University libraries. Safety measures. Work study. Information Technology.

\section{RESUMEN}

La tecnología de identificación por radiofrecuencia (RFID) se viene destacando como una herramienta para automatización, seguridad y gestión de acervos de bibliotecas. El presente artículo describe el proceso inicial de implantación de tecnología RFID en el acervo de la Biblioteca del Centro Universitário Univates (UNIVATES), evidenciando los recursos humanos y de informática involucrados.El tiempo entre planeamiento y ejecución de la grabación y del etiquetado ocurrió en el período de noviembre de 2013 hasta marzo de 2014. Se concluye que el proceso de preparación del acervo para recibir esta tecnología es demorado y costoso, sin embargo, el adecuado planeamiento,

\footnotetext{
1 Formada em Biblioteconomia pela UFRGS, com especialização em Tecnologias da Informação e Comunicação na Educação pela FURG. Porto Alegre, Rio Grande do Sul - Brasil. http://orcid.org/0000-00018960-377X. Email: nalin.ferreira@gmail.com

${ }^{2}$ Mestre em Computação Aplicada pela Universidade do Vale do Rio dos Sinos. Professor do Centro de Ciências Exatas e Tecnológica do Centro Universitário Univates. Lajeado, Rio Grande do Sul - Brasil. http://orcid.org/0000-0003-1936-4093. Email: willianvalmorbida@hotmail.com.
} 
bien como la utilización de recursos de la tecnología de la información que posibiliten administrar todo el proceso, permiten mayor confiabilidad y agilidad.

PALABRAS CLAVE: Identificación por radiofrecuencia. Biblioteca universitaria. Seguridad. Flujo de trabajo. Tecnología de la información.

\section{INTRODUÇÃO}

Atualmente as bibliotecas têm buscado formas de modernizar e ampliar a oferta de recursos e serviços aos seus usuários, tendo para isto adotado tecnologias de informação e computação. Dentre estas tecnologias, tem se destacado a identificação por radiofrequência (RFID) para automação e segurança, permitindo às bibliotecas um maior controle sobre seu acervo físico, gerenciamento das informações e o aumento da autonomia dos usuários.

Este artigo apresenta o processo de etiquetagem RFID dos materiais da biblioteca do Centro Universitário Univates (UNIVATES), descrevendo o processo de colagem e gravação das etiquetas, recursos humanos e de informática envolvidos. O planejamento e execução da colagem e gravação das etiquetas ocorreram entre o período de novembro de 2013 a março de 2014. Ao final do processo, mais de 130 mil materiais da biblioteca receberam etiquetas RFID.

Este artigo está estruturado conforme segue: a seção 2 apresenta os conceitos e tecnologias relacionadas. A Seção 3 apresenta informações institucionais. Na quarta seção é descrito o processo de etiquetagem e gravação das etiquetas RFIDs, assim como os recursos humanos e de TI envolvidos no processo. Por fim, a Seção 5 apresenta as considerações finais.

\section{CONCEITOS E TECNOLOGIAS}

Percebe-se uma necessidade crescente da automação de recursos e serviços, principalmente no âmbito das bibliotecas universitárias, sendo que as mesmas são vistas como instituições voltadas ao suporte à produção e divulgação de informações e conhecimento científico.

A adoção de tecnologias de automação em bibliotecas traz como benefícios a rapidez, agilidade e eficiência no atendimento e prestação de serviços, isto é, a otimização das atividades não só com relação aos usuários, como também em relação às rotinas técnico administrativas da biblioteca e do gerenciamento da informação. Dentre as principais possibilidades trazidas pela adoção da tecnologia RFID encontram-se a oferta de serviços de autoatendimento, inventário e segurança contra furtos.

Segundo o IBICT, (199?) automação de bibliotecas são as diferentes utilizações dadas a equipamentos de processamento eletrônico de dados em atividades ligadas à administração em bibliotecas, centros de administração, serviço de informação e órgãos similares. Essas atividades incluem a seleção e aquisição de material bibliográfico, catalogação, recuperação, 
serviços de empréstimos, dentre outras. Entende-se, então, por automação de bibliotecas a utilização de tecnologias da informação nas rotinas e serviços de uma biblioteca.

Atualmente, um dos principais objetivos para adoção da tecnologia RFID em bibliotecas está na necessidade de aumentar a eficiência dos processos e reduzir os custos relacionados à manutenção do acervo. "A automação e o auto-atendimento podem ajudar as bibliotecas de todos os tamanhos alcançarem estes objetivos. A tecnologia também pode melhorar a circulação e controle do acervo, o que ajuda a alocar recursos humanos e financeiros" (SOARES, et al., 2012). Da mesma forma, afirmam Viera, et al (2007), que diversas bibliotecas no mundo todo têm implementado esta tecnologia para agilizar as diversas atividades das bibliotecas e fornecer novos serviços, entre eles: o auto-empréstimo e a auto-devolução de materiais, inventário mais ágil e segurança contra furtos.

A identificação por radiofrequência foi concebida com a finalidade de permitir que etiquetas coladas aos materiais pudessem se auto identificarem perante um receptor de rádio. Estas etiquetas têm sido utilizadas para as mais diversas finalidades, sendo agora também adotadas em livros no âmbito de bibliotecas (EDWARDS; FORTUNE, 2008). O sistema incorpora a funcionalidade antifurto reservando um bit de segurança na própria etiqueta, cujos estados ( $1=$ ativo, 0 =inativo) podem ser detectados nos portões de detecção, geralmente localizadas à saída da biblioteca, substituindo, dessa forma, as tarjas magnéticas atualmente utilizadas por algumas bibliotecas (VIERA, et al, 2007).

Uma etiqueta RFID típica compreende a um microchip e uma antena. O dispositivo inteiro (incluindo o chip) é empacotado como uma etiqueta adesiva de papel fino que pode vir em uma variedade de formas e tamanhos adequados para a rotulagem de livros, vídeos, DVDs e CDs-etc. Etiquetas RFID podem ser aplicadas a recursos de bibliotecas de forma a melhorar tanto a gestão de acervo e quanto a segurança (EDWARDS; FORTUNE, 2008).

Dispositivos com suporte à tecnologia RFID, como estações de trabalho, unidades de autoatendimento e portões de segurança, podem "interrogar" as etiquetas e lê-las, identificando o item o qual a mesma está colada. Estes equipamentos também podem ler a informação de segurança, que é utilizado para disparar um alarme quando o material é deslocado para perto de um sensor, tal como portões de segurança de uma biblioteca (EDWARDS; FORTUNE, 2008).

Bibliotecas utilizam estas etiquetas em seus itens para promover identificação durante o empréstimo, devolução, inventário e controle antifurto. Alguns dos benefícios da adoção desta tecnologia são (NISO, 2012):

a) Redução de processos manuais, erros e movimento repetitivo;

b) Aprimoramento da experiência dos usuários através da disponibilização de estações de autoatendimento;

c) Redução de tempo gasto na busca por itens;

d) Sistema integrado de segurança. 
Além destes, também podem ser citados a agilidade nos inventários, e gestão do acervo. Os desdobramentos destes benefícios podem poupar horas de trabalho técnico na biblioteca, liberando o bibliotecário para realizar outras atividades de forma a qualificar os processos internos e externos.

A próxima sessão descreve o contexto da biblioteca da UNIVATES.

\section{INSTITUCIONAL}

A UNIVATES localiza-se na cidade de Lajeado (RS), na região do Vale do Taquari, e trata-se de uma universidade comunitária, participante do Consórcio das Universidades Comunitárias Gaúchas (COMUNG). Universidades Comunitárias são criadas pela sociedade civil e pelo poder público local, sendo reconhecidas pelas comunidades regionais como um importante fator de desenvolvimento. São instituições sem fins lucrativos, com gestão democrática e participativa, e tem como característica, reinvestir todos os resultados na própria atividade educacional. O envolvimento direto da comunidade acontece através dos conselhos e na própria gestão (SCHMIDT, 2009).

A Biblioteca da UNIVATES, no ano de implantação da tecnologia RFID, contava com um acervo circulante de aproximadamente 130 mil livros, 48 mil fascículos de periódicos, 2 mil exemplares de material de referência, além de CDs, DVDs e outros materiais. Realiza em média 30 mil empréstimos por mês e atende um público de aproximadamente 15 mil usuários entre alunos, funcionários, professores, ex-alunos além da comunidade externa. Este público é proveniente de 45 cursos de graduação, 13 cursos técnicos e 24 cursos de pós-graduação e 50 cursos de extensão universitária.

A função primordial de uma biblioteca universitária é suprir os mecanismos informacionais de uma comunidade acadêmica, sejam estas informações técnicas, científicas ou literárias, no que se refere às atividades do tripé Ensino, Pesquisa e Extensão, como afirma Silveira (2014). Sendo esta uma biblioteca universitária, existe uma preocupação em manterse moderna e atualizada com as novas tecnologias, pois se percebe que há uma grande influência diária da Tecnologia da Informação (TI) em todas as atividades realizadas, e para isso, é necessário constantemente modernizar suas estruturas organizacionais e de prestação dos seus serviços.

Já há algum tempo surgiu a necessidade da UNIVATES oferecer uma biblioteca com um adequado gerenciamento de acervo e possibilitando maior autonomia a sua comunidade acadêmica e regional. A idealização de uma biblioteca funcional e que pudesse oferecer aos seus usuários os benefícios trazidos pela adoção da tecnologia RFID resultou em um projeto de implementação desta tecnologia. A decisão de adotar a tecnologia RFID demandou um detalhado planejamento com escalas de trabalho, treinamentos internos, tomadas de decisão, definição de workflow e criação de software.

Vários fornecedores e bibliotecas que já utilizavam a tecnologia RFID aplicada à automação foram consultados no processo inicial, antes da adoção da tecnologia. Neste período percebeu-se que grande parte destas bibliotecas utilizam sistemas híbridos, resultante 
da integração do RFID com tecnologias previamente adotada para segurança do acervo, geralmente tecnologia eletromagnética (EM).

A Biblioteca da UNIVATES, por ainda não utilizar nenhuma tecnologia para segurança ou automação, partiu para a adoção de uma solução única, sendo pioneira no país na adoção da solução mais completa adotando tecnologia puramente RFID. Dentre os possíveis fornecedores de uma solução RFID para a Biblioteca da UNIVATES, a empresa Bibliotheca ${ }^{3}$ foi escolhida.

A próxima seção apresenta a descrição detalhada do planejamento e execução do processo de gravação e etiquetagem realizados na Biblioteca da UNIVATES.

\section{PROCESSO DE ETIQUETAGEM E GRAVAÇÃO}

O processo de etiquetagem e gravação consistiu na colagem da etiqueta RFID, colagem da etiqueta de proteção e gravação das informações na etiqueta. $O$ processo de gravação foi feito através da leitura do código de barras de cada material e consequente registro na etiqueta RFID. Além do código de barras, foi também gravada a identificação da biblioteca da UNIVATES como uma informação fixa em cada etiqueta.

Para o processo de gravação de etiquetas foram utilizadas duas ferramentas: equipamento móvel de conversão (SmartStation) e do software de conversão (SmartStation Manager). O SmartStation consiste em duas peças individuais de software, codificação e circulação. O equipamento consiste de um notebook e um leitor/gravador, que permite realizar a gravação das etiquetas RFID.

O ILS (Integrated Library System) utilizado pela Biblioteca da UNIVATES assume também um importante papel neste contexto, visto que parte do gerenciamento do processo realizado foi realizado com seu suporte.

Desta forma, a Seção 4.1 descreve os recursos disponíveis no ILS da Biblioteca da UNIVATES, assim como sua utilização para gerenciamento do processo de etiquetagem e gravação dos RFIDs. A Seção 4.2 descreve os recursos humanos dedicados ao processo, assim como a definição do processo em si. Por fim, a Seção 4.3 descreve os recursos de TI utilizados e especialmente desenvolvidos para suporte a este processo.

\section{Recursos do ILS}

3 A Bibliotheca é uma empresa dedicada ao desenvolvimento, implantação, suporte e assistência de soluções RFID, híbridas EM/RFID e de código de barras para bibliotecas, visando facilitar e melhorar os processos internos de bibliotecas. A empresa também oferece um trabalho contínuo de gerenciamento de projetos, iniciando, planejando, executando e monitorando toda a instalação da solução RFID adotada por bibliotecas (BIBLIOTHECA, 2016). 
A Biblioteca da UNIVATES utiliza desde 2000 o ILS Gnuteca para o gerenciamento de seu acervo. O Gnuteca é um sistema de automação e gestão de bibliotecas, que respeita os padrões ISIS e MARC21 de acordo com as indicações da Library of Congress (SOLIS). Inicialmente o Gnuteca foi desenvolvido pelo Centro de Processamento de Dados (CPD) da UNIVATES, sendo que, parte deste grupo formou uma cooperativa de serviços chamada Solis, que posteriormente deu continuidade na manutenção e desenvolvimento do sistema.

O ILS utilizao pela Biblioteca da UNIVATES permite realizar uma série de configurações, como a criação de novos estados de exemplar (por exemplo: disponível, emprestado, reservado etc). Este recurso permitiu a criação do estado de exemplar denominado RFID. Associado ao estado de exemplar RFID, foram criados um conjunto de regras de circulação de material, que determinam as operações que podem ser realizadas sobre exemplares neste estado, assim como as transições de estado resultantes destas operações.

Além da troca de estado, o ILS também permite o agendamento de trocas, esta funcionalidade permite que para materiais em circulação (como por exemplo, materiais emprestados) seja realizado um agendamento de troca para determinado estado. Assim quando o material for devolvido, o ILS alertará ao operador que existe um agendamento para o estado escolhido. O processo de agendamento de estados possui prioridade sobre o processo de reserva, ou seja, ao devolver o material, agendamentos serão atendidos em detrimento as reservas.

\section{Recursos humanos e definição do processo}

Para etiquetagem e gravação das etiquetas RFID dos materiais da Biblioteca da UNIVATES foi necessário definir o fluxo do processo, definir a infraestrutura e proceder com a execução. A Biblioteca da UNIVATES contava na época com uma equipe de 3 bibliotecários, 1 assistente, 1 analista de TI e 27 auxiliares.

Durante todo processo de etiquetagem e gravação, a biblioteca permaneceu em funcionamento, com horário normal e com acervo aberto aos usuários, de modo que buscouse definir um fluxo de processo que trouxesse o mínimo de impedimentos ao seu funcionamento, sendo ao mesmo tempo eficiente para execução da atividade proposta, levando em consideração características do acervo, mão de obra disponível e demais atividades do setor. Desta forma, os funcionários alocados para o processo de etiquetagem buscaram reorganizar suas atividades dando prioridade ao novo processo. Para execução do processo foi escolhido o período de novembro a março por contemplar o período de recesso das aulas, com esperada redução no fluxo de usuários na biblioteca.

Visando facilitar a colagem das etiquetas nos materiais, alguns cuidados foram tomados, tendo em vista que há alguns detalhes a serem considerados como, por exemplo, uma distância da lombada e parte inferior do exemplar, para uma melhor leitura da etiqueta pelo sistema RFID, e para evitar que haja sobreposição à etiqueta de lombada e protelivro 
utilizados pela biblioteca. Para isto, foram criadas réguas em formato de "L", com marcações a cada $2 \mathrm{~cm}$.

Como forma de controle do processo de etiquetagem, o acervo foi subdividido em intervalos de classificação, que denominamos de classes. Desta forma, ao término da etiquetagem e gravação de cada intervalo, geraram-se relatórios e foram executados procedimentos buscando identificar e corrigir falhas ocorridas durante o processo.

Para a etiquetagem dos materiais presentes no acervo, a equipe de funcionários da biblioteca foi organizada em duplas e manteve-se um contingente mínimo para desempenho das tarefas de atendimento e administrativas. As duplas iniciaram o processo, sendo responsáveis pela colagem das etiquetas RFID e etiqueta de proteção. Logo atrás das duplas, um funcionário foi encarregado pelo processo de gravação das etiquetas utilizando a estação móvel de conversão (SmartStation). Rotinas com horários e responsabilidades para estas atividades foram pré-definidos em escalas.

Para o processo de etiquetagem dos materiais em circulação definiu-se um fluxo de processo conforme apresentado na Figura 1. Este processo foi rigorosamente seguido para todos os materiais e aplicado no momento de serem repostos no acervo.

Neste procedimento buscou-se identificar se cada material pertence a um intervalo que está sendo gravado ou se o intervalo correspondente já foi gravado e o material ainda possui um agendamento para o estado RFID, de modo a tornar necessária a etiquetagem $\mathrm{e}$ gravação destes materiais antes de serem guardados no acervo.

O restante dos passos do processo se resume em separar os materiais em uma estante específica, etiquetar, efetuar a gravação da etiqueta, tirar o material do estado RFID e devolver o material (buscando identificar pendências, como, por exemplo, reservas). Materiais que não atendem as características citadas acima devem ser repostos diretamente no acervo, visto que, ou já foram etiquetados e gravados ou passarão por este processo no momento que sua classe correspondente for iniciada. 


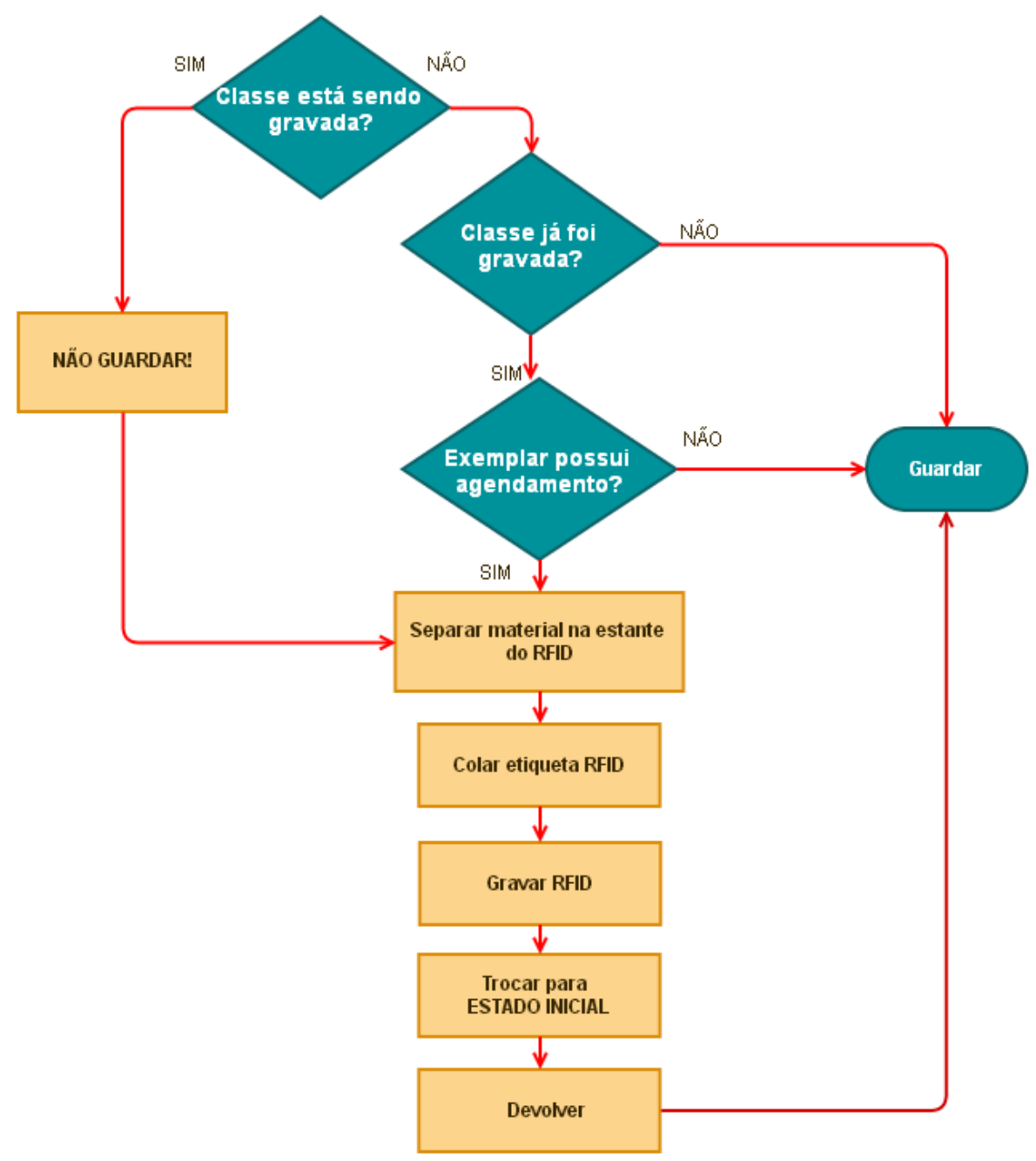

FIGURA 1 - Fluxo do processo de etiquetagem e gravação Fonte: Os autores

\section{Recursos de Tecnologia da Informação}

Objetivando manter os serviços de circulação de material da biblioteca, e para promover o completo gerenciamento da etiquetagem e gravação das etiquetas RFID foi desenvolvido um software que faz a leitura de arquivos de log gerados pelo software de gravação das etiquetas, assim como efetua o acesso ao banco de dados do ILS da biblioteca, com vistas a identificar erros no processo e itens não gravados no acervo ou em circulação.

O software SmartStation Manager, utilizado para gravação das etiquetas RFID não possibilita a comunicação direta com o ILS da biblioteca, no entanto, o mesmo efetua a gravação de arquivos de $\operatorname{logs}$ das operações realizadas. A existência de tais arquivos possibilitou o desenvolvimento de um software, nomeado RFIDAdmin, para controle do 
processo a partir das informações disponibilizadas, como a data e hora de gravação de uma etiqueta, a identificação do exemplar e o ID interno da etiqueta RFID.

Em computação, log de dados é uma expressão utilizada para descrever o processo de registro de eventos relevantes num sistema computacional. Esse registro pode ser utilizado para restabelecer o estado original de um sistema ou para que um administrador conheça o seu comportamento no passado. Um arquivo de log pode ser utilizado para auditoria e diagnóstico de problemas em sistemas computacionais.

O software desenvolvido (Figura 2) possui uma interface simples que, no entanto, traz as principais funcionalidades necessárias ao gerenciamento do processo de etiquetagem e gravação das etiquetas RFIDs.

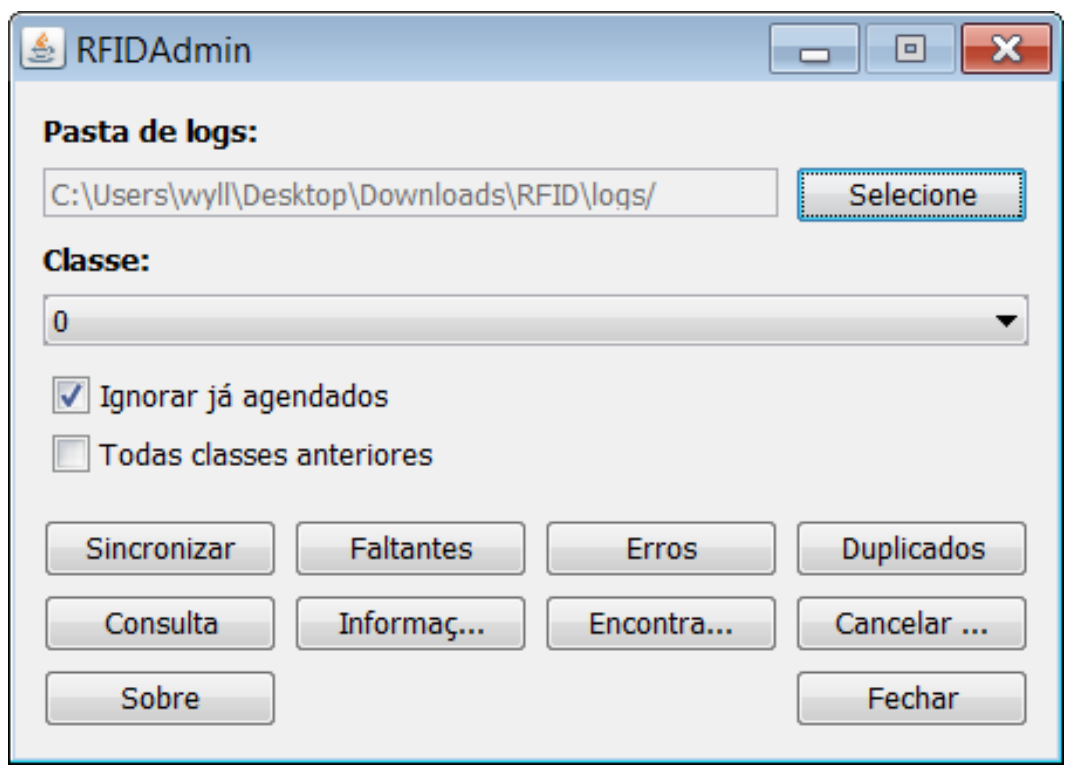

FIGURA 2 - RFIDAdmin: tela principal do software desenvolvido Fonte: Os autores

O software permite selecionar a classe a ser verificada, de acordo com a subdivisão mencionada, ou ainda processar todas as classes já etiquetadas e gravadas (Figura 3). 


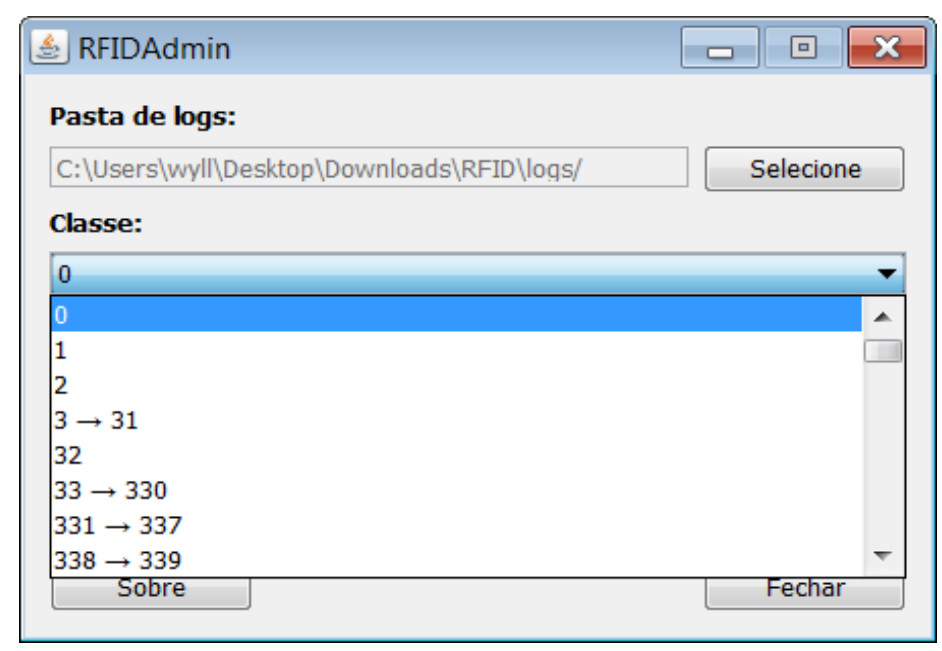

FIGURA 3 - RFIDAdmin: listagem da subdivisão de classes Fonte: Os autores

As principais funcionalidades presentes no software desenvolvido são:

a) Sincronizar: realiza leitura dos arquivos de log, conforme pasta indicada pelo usuário, formando uma base de dados de itens já processados;

b) Faltantes: permite obter uma listagem de materiais que ainda não foram processados. A listagem pode ser gerada de todas as classes já processadas ou de uma classe específica. Também é possível omitir da listagem os itens já agendados.

c) Erros: permite obter uma listagem de itens que apresentam algum erro de gravação como, por exemplo, o código do exemplar que não corresponde a nenhum item do acervo. Geralmente identifica erros causados por falhas de leitura do código de barras;

d) Duplicados: permite obter uma listagem de itens que tiveram sua identificação gravada em mais de uma etiqueta RFID. A disponibilidade do ID interno da etiqueta possibilita a identificação de exemplares duplicados;

e) Consulta: permite consultar itens já processados a partir de seu código de exemplar, ID da etiqueta RFID e ID do registro no banco de dados;

f) Informações: disponibiliza informações gerais sobre os itens processados, como a quantidade total e quantidade já processada;

g) Encontrados: permite obter uma listagem de itens que foram processados, mas que no ILS da biblioteca encontram-se como baixados, desaparecidos ou mesmo em algum estado que não deveria estar no acervo;

h) Cancelar agendamentos: permite obter uma listagem materiais com agendamentos que não foram atendidos por algum erro de processo, mas que já se encontram etiquetados e gravados.

A listagem de itens faltantes, erros encontrados e etiquetas duplicadas são gerados e exportados para um arquivo HTML, apresentando as informações conforme a Figura 4: 
código do exemplar, atual estado, possui agendamento e localização (Classificação Decimal Universal - CDU e Cutter).

A listagem de faltantes permite identificar itens que foram, por alguma razão, pulados durante a gravação, de modo que possam ser localizados no acervo e gravados. Ela também identifica os materiais que já tiveram seus agendamentos atendidos, estando os mesmos marcados com o estado RFID.

\begin{tabular}{|llll|}
\hline 1 & 00135381 Disponível & \multicolumn{1}{c}{001.891} & C517m.2 \\
2 & 00135382 Disponível & \multicolumn{1}{c}{001.891} & C517m.2 \\
3 & 00014955 Emprestado & Agendado 070:800.863 & L1741 \\
4 & 00032344 Emprestado & Agendado 028.1/.8 & L191d \\
5 & 00048111 Emprestado & Agendado 001.891 & P258a \\
6 & 00048155 Emprestado & Agendado 001.891 & P258m \\
7 & 00053662 Emprestado & Agendado 001.891 & P258m \\
8 & 00057157 Emprestado & Agendado 028 & P912 \\
9 & 00066812 Emprestado & Agendado 001.891 & S487m \\
10 & 00068464 Emprestado & Agendado 070.325:800.866 & B662e \\
11 & 00069965 Emprestado & Agendado 001.1 & C679 \\
12 & 00072533 Emprestado & Agendado 001.891:378 & A553c \\
13 & 00076916 Emprestado & Agendado 028:681.3 & L533 \\
14 & 00077130 Emprestado & Agendado 070:659.4 & A846 \\
15 & 00078089 Emprestado & Agendado 001.891:378 & A553c \\
16 & 00078145 Emprestado & Agendado 001.891 & B662m \\
17 & 00082458 Emprestado & Agendado 070:659.4 & K83a \\
18 & 00084864 Emprestado & Agendado 070 & L174i \\
\hline
\end{tabular}

FIGURA 4 - RFIDAdmin: exemplo parcial de relatório gerado Fonte: Os autores

A Figura 5 apresenta a tela de consulta do software. A partir desta tela é possível consultar em um banco de dados que contem o registro de todos os materiais já gravados, disponibilizando data e horário da gravação, assim como o ID interno da etiqueta em que as informações foram gravadas. 


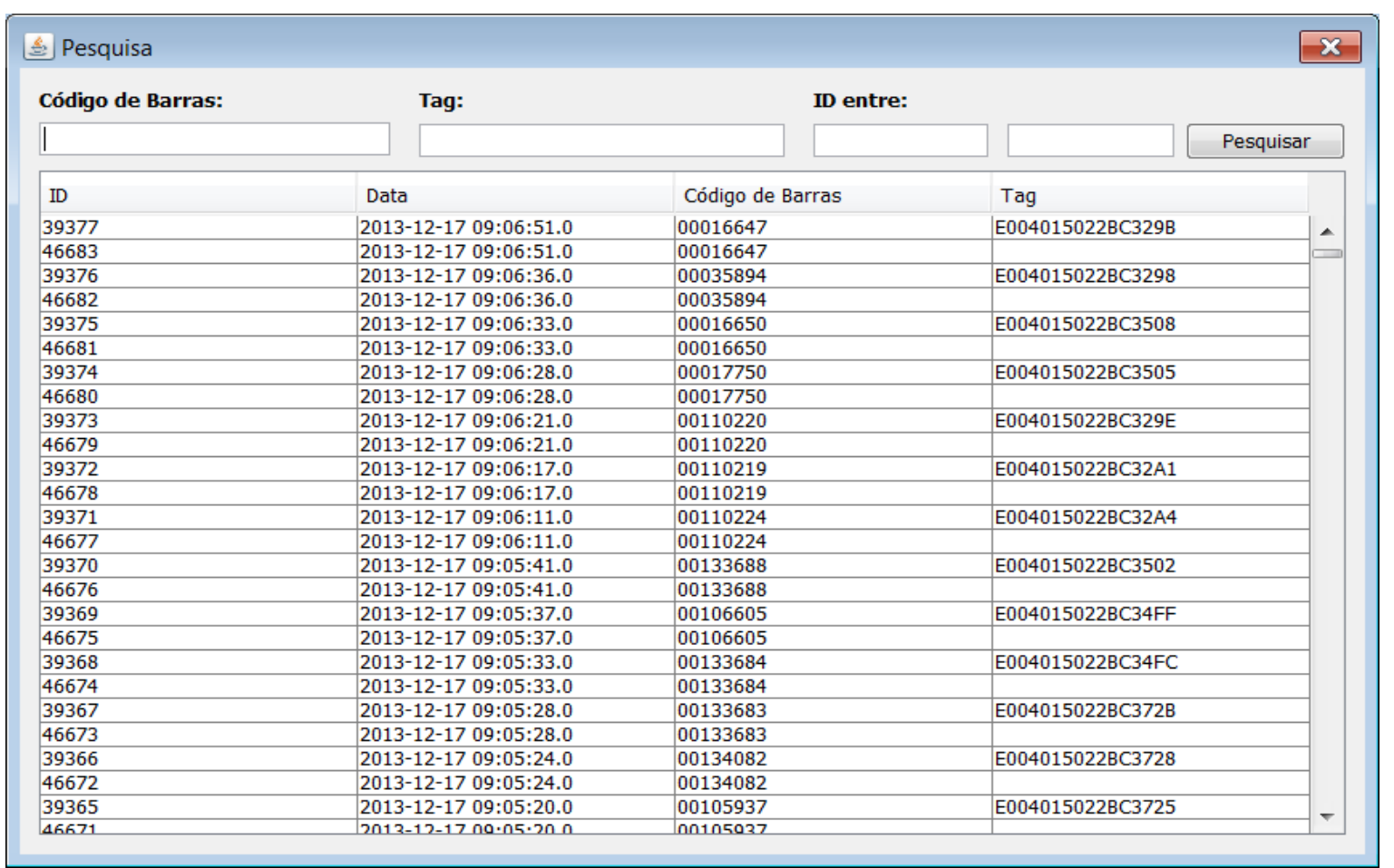

FIGURA 5 - RFIDAdmin: tela de consulta de itens já gravados Fonte: Os autores

A partir da sincronização periódica dos logs de dados, a ferramenta RFIDAdmin deu suporte ao gerenciamento do processo de etiquetagem e gravação dos RFID, permitindo a identificação de problemas e sua rápida correção, assim como identificar os materiais que não foram etiquetados ou gravados, de modo a resultar em uma maior confiabilidade do processo, garantindo que nenhuma ou uma mínima parcela conhecida dos materiais não passou pelo processo.

\section{CONSIDERAÇÕES FINAIS}

A tecnologia RFID ainda é considerada relativamente nova, mas vem ganhando adeptos entre as bibliotecas atuais, devido principalmente aos benefícios trazidos pelos serviços de autoatendimento e segurança. Por outro lado, sua implementação demanda alto investimento inicial, mão de obra e planejamento.

O processo de preparação do acervo para receber esta tecnologia é demorado e custoso, contando ainda com diversos inconvenientes e complicações principalmente quando mantem-se o funcionamento regular da biblioteca em paralelo. Entretanto, o adequado planejamento, assim como a utilização de recursos da tecnologia da informação que possibilitem gerenciar todo o processo, permite maior confiabilidade e agilidade.

Ao final deste processo, 130 mil itens foram gravados, no período de 2 meses e 20 dias. O processo demandou um criterioso planejamento inicial, com estabelecimento de

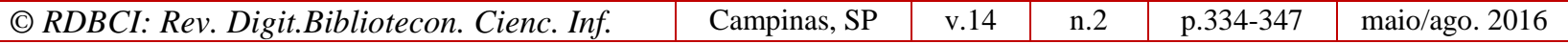


metas e definição de recursos de informática e escalas de trabalho, e ao final, ficou evidente a importância deste planejamento, para corrigir eventuais falhas que ocorreram durante o processo.

Ainda assim, a implantação das etiquetas RFID e gravação é um processo contínuo, pois o crescimento do acervo é constante. Sobre os benefícios efetivos da implementação do sistema RFID, estes só serão percebidos de fato quando a tecnologia estiver efetivamente em operação contando com equipamentos de auto empréstimo, auto devolução, leitor de inventário e portões de segurança.

\section{REFERÊNCIAS}

BIBLIOTHECA. Quem $\quad$ somos. 2016.20 Disponível <http://www.bibliotheca.com/1/index.php/pt/>. Acesso em: 23 dez. 2013.

EDWARDS, Simon; FORTUNE, Mick. A Guide to RFID in Libraries. Book Industry Communication, 2008.

IBICT. III PLANO BÁSICO DE DESENVOLVIMENTO CIENTÍFICO E TECNOLÓGICO. Ação Programada em ciência e Tecnologia. Brasília: IBICT, [199?]. v. 29

NISO. RFID in U.S. Libraries: a recommended practice of National Information Standasds Organization. Niso: Baltimore, 2012.

SCHMIDT, João Pedro (Org.). Instituições Comunitárias: instituições públicas não-estatais. Santa Cruz do Sul: EDUNISC, 2009.

SILVEIRA, Nalin Ferreira da. Evolução das bibliotecas universitárias: information commons. Revista ACB: Biblioteconomia em Santa Catarina, Florianópolis, v.19, n.1, jan./jun., 2014.

SOARES, Eva Falcão; et al. Vantagens e desvantagens da aplicação da tecnologia RFID na automação de uma biblioteca de uma Universidade Federal. In: Simpósio de engenharia De Produção Nordeste, 7, 2012, Mossoró. Anais... Mossoró: Serprone, 2012.

SOLIS. Gnuteca. Disponível em: <http://www.solis.com.br/gnuteca>. Acesso em: 23 dez. 2013.

VIERA, Angel Freddy Godoy; VIERA, Sonia Dominga Godoy; VIERA, Lourdes Elizabeth Godoy. Tecnologia de identificação por radiofreqüência: fundamentos e aplicações em automação de bibliotecas. Encontros Bibli: Revista Eletrônica De Biblioteconomia E Ciência Da Informação, Florianópolis, n. 24, 2007. 

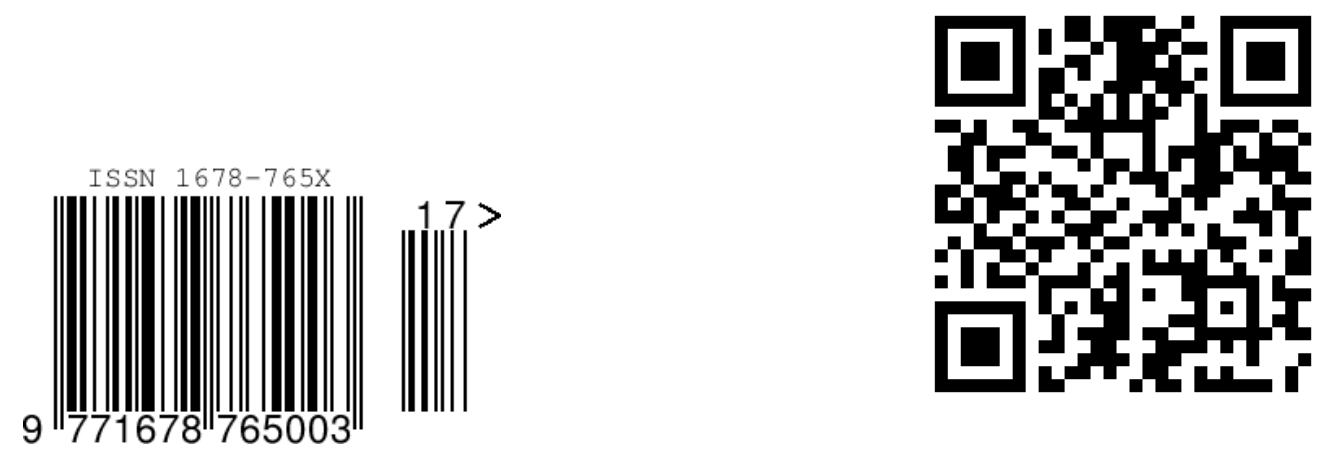